\title{
Presentation of a rare case: IgA deposit disease in pregnancy
}

\author{
Onur Karaaslan $^{1^{\star}}$ and Erkan Şimşek ${ }^{2}$ \\ ${ }^{1}$ Department of Obstetrics and Gynecology Hakeari Public Hospital, Hakkari, Turkey \\ 2Department of Obstetrics and Gynecology Kanuni Sultan Suleyman Research and Traning Hospital, Istanbul, Turkey
}

\begin{abstract}
Linear $\operatorname{Ig} \mathrm{A}$ dermatosis is a rare autoimmune bullous skin disease characterized by accumulation of $\operatorname{linear} \operatorname{Ig} \mathrm{A}$ along the basal membrane zone and formation of subepidermal bullae. A 27 year-old female case who developed blister on the scalp (hairy skin) in 11 th gestational week used dapsone and prednisolone during her pregnancy. In this case, the fetal and maternal outcomes of $\operatorname{IgA}$ deposit disease and used medications are presented.
\end{abstract}

Key Words: IgA deposite, pregnancy, dapsone

\section{Introduction}

Pregnancy dermatoses represent a group of diseases involving pruritic inflammatory skin diseases associated with pregnancy and/or postpartum period. Some dermatoses affect only the mother with severe itching, while others carry fetal risks such as fetal distress, prematurity and stillbirth.

Linear IgA dermatosis (lad), not specific to pregnancy; is a rare autoimmune bullous skin disorder characterized by the accumulation of linear IgA along the basal membrane zone and the formation of subepidermal bullae. The disease is more common among younger adults. Clinically, vesiculobullous rash is observed in skin and mucous membranes. In this case, a female case who complained of itchiness in the hairy skin on the 11 th week of pregnancy and then develops blisters under her scalp is presented.

\section{Case report}

Twenty-seven year old female patient, first pregnancy, last mensturation period: 17/09/2016 old usg was measured on 6/11/2016 as crownrump length (crl) 6+4. There is no known systemic disease and regular drug use in the patient's story. The patient who started complaining of pruritus on hairy skin on the 11th week of pregnancy was seen to have developed blister one-week afterwards.

During the following weeks, intense itchiness and redness were observed especially on the back, backwards of the arms, femoral, femur, feet, between breast and formation of plaques containing bullae and vesicles ranging from $2 \mathrm{~mm}$ to $5 \mathrm{~cm}$ with the active sharp edges towards the borders of the erythematous layer in the body, widespread in the abdomen, the supine, the thigh region and presence of post-inflammatory macules and patches with the largest size of $2 \mathrm{~cm}$ diameter and smallest size of $1 \mathrm{~mm}$ diameter in the vicinity of these plaques was monitored (Figure 1,2). The patient who applied with these complaints was admitted to the hospital with the pre-diagnosis of gestational pemphigoid at the 13th week of pregnancy and $40 \mathrm{mg}$ of prednisolone was started. At week 16, subepidermal bulla and neutrophilic inflammatory infiltrates on the superficial dermis were histopathologically observed according to the results obtained from punch biopsy. In direct immunofluorescence, linear Ig A deposition was observed, and $100 \mathrm{mg} /$ day dapsone was included to the treatment.

The patient was admitted to the hospital due to increase in lesions at 21 th of the gestational week with varicella zoster virus infection pre-diagnosis. Prednisolone dose was lowered to $16 \mathrm{mg} /$ day and dapsone was continued at a level of $100 \mathrm{mg} /$ day. Acyclovir $5 * 800 \mathrm{mg}$ tb was completed to 7 days. Dapsone $100 \mathrm{mg} /$ day and prednisolone 40 $\mathrm{mg} /$ day were administered during the period from the 22 nd week until birth for the treatment.

At 23 weeks, maternal and fetal doppler findings were normal and no property of fetus echocardiography was found when investigating second level ultrasoundgraphy. Intracranial 
structures were found to be normal according to gestational week. Other systems were examined in detail and no anomalies were observed.

The patient was admitted to the hospital with amniotic fluid leakage diagnosis at $37+2$ weeks of gestation and underwent a cesarean operation with cephalopelvic disproportion (CPD) indication who gave birth a live male infant weighing $3300 \mathrm{~g}$ with an apgar score of $9 / 10$.

At the third trimester and postpartum period, the lesions of the patient decreased and again increased at the $3^{\text {rd }}$ month of postpartum period. The patient continues to recieve dapsone $100 \mathrm{mg}$ and prednisolone $40 \mathrm{mg}$ daily.

\section{Discussion}

According to Ambros-Rudolph et al. (1) gestational dermatoses can be classified as: Pemphigoid Gestation (PG), Polymorphic Eruption of the Pregnancy (PEP), Intrahepatic Cholestasis of the Pregnancy (ICP) and Atopic Eruption of the Pregnancy (AEP). In this study,

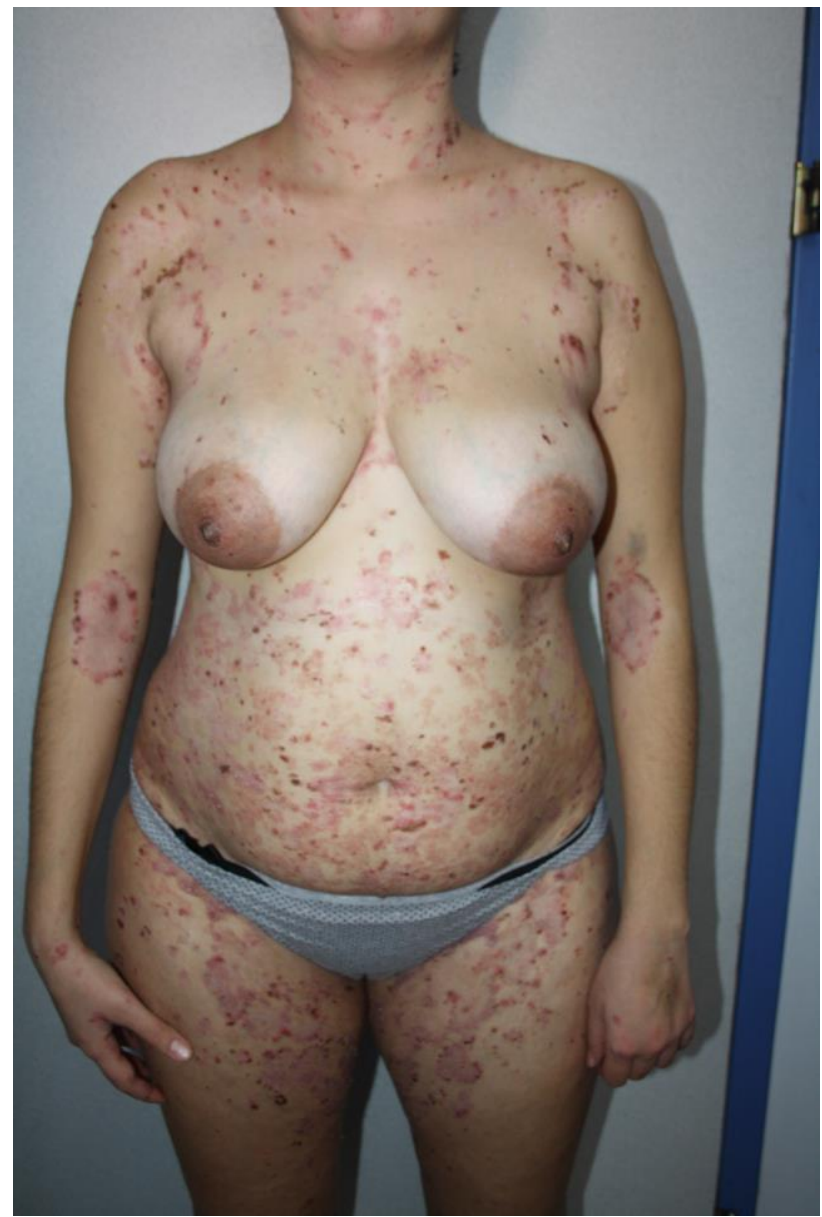

Fig. 1. Bullous lesions on the front of the body.
505 itchy pregnant patients who applied to two university hospitals in England and Austria in 2006 were evaluated and $49.7 \%$ of the cases were diagnosed with gestational eczema.

Linear $\operatorname{Ig} \mathrm{A}$ dermatosis is a rare dermatosis which is not specific to pregnancy. Linear $\operatorname{IgA}$ dermatosis is a rare autoimmune bullous skin disease characterized by a linear $\operatorname{Ig} \mathrm{A}$ accumulation band along the basal membrane zone and subepidermal bullae formation.

In the etiology it is thought that drugs such as vancomycin, penicillin, cephalosporin, captopril, lithium, diclofenac and the gastrointestinal tract and autoimmune diseases such as infections, ulcerative colitis, rheumatoid arthritis, systemic lupus erythematosus, glomerulonephritis trigger an immune response. There was no accompanying chronic disease and drug story in our case $(2,3)$.

In the United States, the incidence is 0.6 / 100,000 in adults and 1.6 times more common in women than in men. In a study of patients aged 14-83, the mean age of onset of the disease was determined as 52 (4).

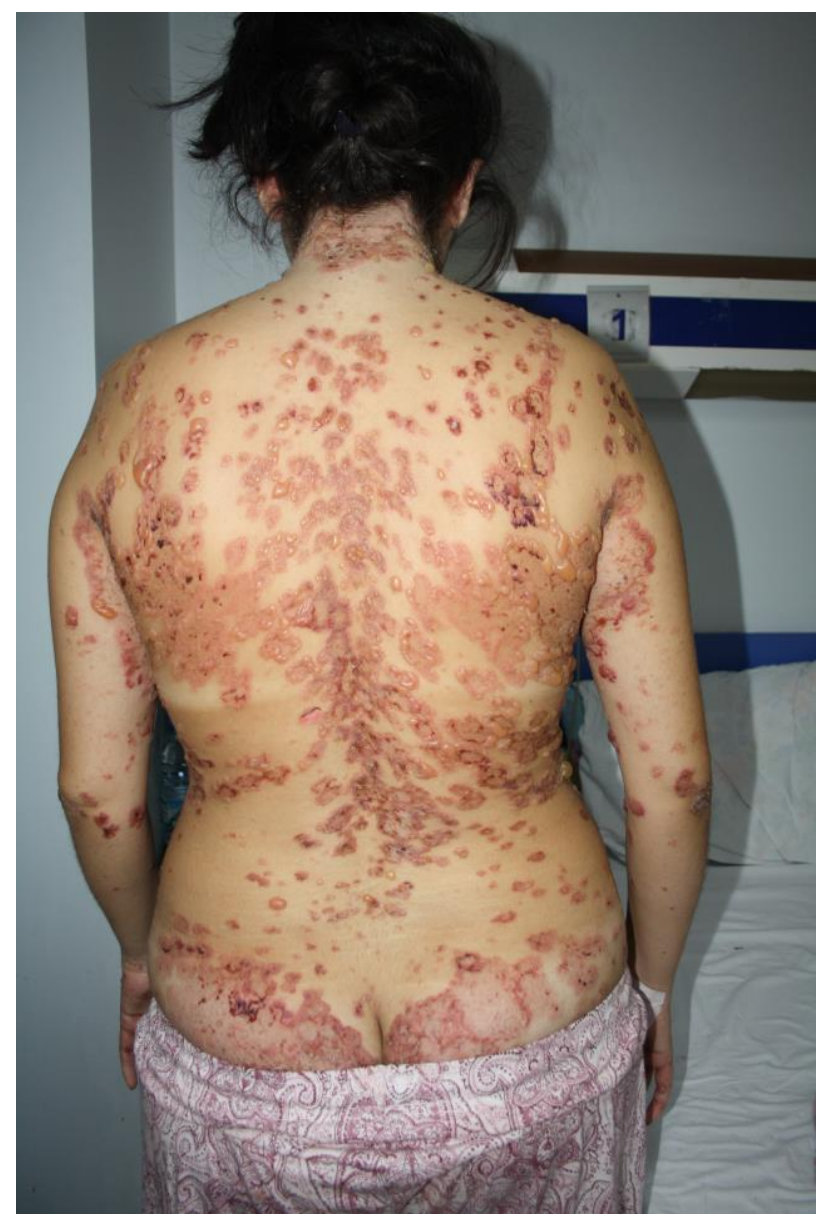

Fig. 2. Bullous and purulent lesions on the back of the body.

East J Med Volume:23, Number:4, October-December/2018 
Clinically it is difficult to distinguish from dermatitis herpetiformis. The most common symptoms are extremities, grouping papules, urticarial plaques, vesicles, and bullae on face and body while also characterized by inflammation, erosion, and scarring in the mucous membranes.

Even though clinical appearance, neutrophil infiltration dominant subepidermal vesicles in biopsy are helpful at diagnosis; the gold standard method is determination of linear Ig A accumulation thorough basal membrane zone in direct immunofluorescence. In our case, direct immunofluorescence examination showed linear $\operatorname{IgA}$ accumulation along the basal membrane $(1,2,5)$. Dapsone is the most common drug currently being used in linear Ig A dermatosis. Dapsone is a derivative of 4,4 diaminophenyl sulphone and listed as category C pregnancy medication. In our case dapsone $100 \mathrm{mg} /$ day and prednisolone $40 \mathrm{mg} /$ day was started at prepartum period $(1,2,5)$.

The pregnancy category of prednol is C. Methylprednisolone passes through placental barrier. It was shown that, in animal experiments, corticosteroids cause fetal development abnormalities including cleft palate, intrauterine growth retardation and neural development defects. However there is no data in the literature showing that use of corticosteroids cause increase of congenital anomaly incidences in human beings. Increase in the number of premature rupture of membrane (PPROM) and low births was observed (6). Topical and systemic steroid, tetracyclin, nicotinamide, mycophenolate mofetil, IVIG, colchicine, erythromycin, trimethoprim, and interferon-alpha are other agents used in therapy $(1,2,5)$.

In a retrospective study of 12 patients with linear Ig A disease in the 10th gestational week; the most remarkable healing was observed in $3^{\text {rd }}$ trimester. In our case the lesions were first time started at $11^{\text {th }}$ gestational week and started to decrease in the last trimester and postpartum period. Dapsone, classified by the FDA as group C agent, is the most commonly used agent in $\mathrm{Ig} \mathrm{A}$ dermatosis and in this study no serious side effects due to dapsone were observed in 11 pregnant women. Relapses are very common in the case of linear Ig A dermatosis, and in 1 case it is seen in 2 hours within postpartum period. The mean relapse time for the 11 patients was found to be 1 - 6 months and for 3 patients the complete remission was achieved after 2 years. In our case, the lesions entering the remission in the last trimester increased again in the $3^{\text {rd }}$ month time period of postpartum. There was no detectable effects of the disease on the fetal outcome and a live male baby weighing $3300 \mathrm{~g}$ with 9/10 apgar score came to the world (7).

$\operatorname{Ig}$ A dermatosis is an uncommon disease. It is rarely seen in pregnancy as well. There are very limited number of cases. For this reason, more cases are needed to better assess effect of disease and medications on fetus and mother health in the follow-up and treatment of these patients.

\section{References}

1. Ambros-Rudolph CM, Müllegger RR, Vaughan-Jones SA, Kerl H, Black MM. The specific dermatoses of pregnancy revisited and reclassified: results of a retrospective two-center study on 505 pregnant patients. J Am Acad Dermatol 2006; 54: 395-404.

2. Akman A. Lineer Ig A Dermatozu ve çocukluk çağının kronik büllü hastalığı. In: Tüzün Y, Gürer MA, Serdaroğlu S,Oğuz O, Aksungur VL, eds, Dermatoloji, 3. Baskı. İstanbul: Nobel Tip Kitapevleri. 2008; 874-880.

3. Cauza k, hinterhuber G, Sterniczky B, et al. Lineer Ig A dermatozun sıradışı klinik görünümü: iki olgu bildirisi. J Am Acad Dermatol Turkish edition 2004; 3188-3192.

4. Norris IN, Haeberle MT, Callen JP, Malone JC. Generalized linear IgA dermatosis with palmar involvement. Dermatol Online J. 2015 Sep 17;21(9). pii: 13030/qt1s3402cj. PubMed PMID: 26437279.

5. Akarasu S, İlknur T, Erdemir Y, et al. Otoimmün büllöz dermatozlarda başlangıç özellikleri ve eşlik eden otoimmün hastalıklar. Dokuz Eylül Üniveristesi Tip Fakültesi Dergisi 2010; 24: 57-63.

6. Corticosteroids during pregnancy. Lockshin MD, Sammaritano LR. Scand J Rheumatol Suppl. 1998;107:136-138.

7. Collier PM, Kelly SE, Wojnarowska F. Linear IgA disease and pregnancy. J Am Acad Dermatol 1994; 30: 407-411. 